\title{
DAS METAMORFOSES DO AMOR N'OS LUSÍADAS: ARMA-AMAR
}

\section{ABOUT THE METAMORPHOSIS OF LOVE IN THE LUSIADS: ARMOUR- AMOUR}

\author{
Mariana Caser da Costa ${ }^{1}$
}

\section{RESUMO}

A leitura detida dos dez cantos constitutivos de Os Lusíadas permite-nos associar o substantivo arma e a forma verbal amar a questões que excedem a casualidade textual ou a ludicidade proveniente da mudança de posição da letra r. Tematicamente, sabemos que "as armas e os barões assinalados" cedem, algumas vezes, espaço ao lirismo, por exemplo, na voz de um capitão que parece deixar sua patente, suas armas, portanto, para armar espetáculos cujo protagonista é o amor. Este artigo pretende pensar sobre a forma como esse jogo de palavras transforma não apenas o campo vocabular, mas, especialmente, o semântico, na extensão do poema: quais efeitos causa na leitura; quais leituras podem ser feitas, contemporaneamente; em que implica a relação entre arma e amar. Ao refletir sobre essas questões a partir das ideias de António Saraiva, Eduardo Lourenço, Luiza Nóbrega, bem como do escritor português contemporâneo Mário Cláudio, dentre outros nomes de relevo no cenário da crítica e da teoria literárias, não pretendemos gerar uma interpretação inovadora do poema, mas reforçar a leitura atual d'Os Lusíadas, em que demandas maneiristas, lúdicas e, especialmente, denotadoras da plasticidade do texto, ressurgem como pontos de relevo na exegese da obra.

PALAVRAS-CHAVE: Os Lusíadas, arma, amar. 


\section{ABSTRACT}

The attentive reading of the ten constitutive cantos of The Lusiads allows us to connect the nouns armour and amour (in Portuguese, the original title intends to relate the noun "weapon" and the verb "love" - which we translate, by meanings of maintaining the wordplay, armour-amour) to issues that exceed the textual coincidence or the ludic results of changing the position of letter $r$. Thematically, we know that the "arms and the heroes" sometimes give place to the lyricism, for instance, in the voice of a captain who seems to leave his military ranks, therefore his armour, to perform scenes in which love is the protagonist. This article intends to think about the way that refereed wordplay transforms not only vocabulary, but particularly semantics along the poem: which effects it causes in the reading; which contempory readings can be done; what are the consequences of the relation between armour and amour. Reflecting about those points, from the ideas of António Saraiva, Eduardo Lourenço, Luiza Nóbrega, as well as contemporary Portuguese writer Mário Cláudio, among other important names in literary critics and theory scene, we do not aim to offer an innovative interpretation of the poem, but to reinforce the current reading of The Lusiads, in which Mannerist, ludic, and plastic demands rise as significant points in the exegesis of the work.

KEYWORDS: The Lusiads, armour, amour.

A Morte, que da Vida o nó desata,/ Os nós, que dá o Amor, cortar quisera/ Na Ausência, que é contr'ele espada fera, / e co Tempo, que tudo desbarata.// Duas contrárias, que üa a outra mata,/ a Morte contra o Amor ajunta e altera:/ üa é Razão contra a Fortuna austera,/ outra, contra a Razão, Fortuna ingrata.// Mas mostre a sua imperial potência/ A Morte em apartar dum corpo a alma,/ duas num corpo o Amor ajunte e una;// porque assi leve triunfante a palma,/ Amor da Morte, apesar da Ausência,/ Do Tempo, da Razão e da Fortuna. (Luís de CAMÕES)

O soneto camoniano que epigrafa este artigo apresenta os fios da meada que, com cautela, juntamos: amor e espada, que é arma. O cuidado justifica-se pela vasta gama de estudos competentes e consagrados acerca das questões linguísticas, especialmente as que remetem ao jogo - palavra tão contemporânea, mas também tão presente na cultura maneirista - da labiríntica obra camoniana, cujas dobras revelam um tecido de estruturas gramaticais complexas, inversões, oposições, anagramas, enfim, jogos de ideias e de palavras sobre os quais ora nos debruçamos. 
Ainda, o soneto epigrafado apresenta-nos os pares "Vida/ Morte" e "Fortuna/ Razão". À Razão da Morte cabe desatar o nó da Vida, que é, aponta-nos o poema, Fortuna; entretanto, uma é arma contra a outra, pois uma fere a existência da outra: complementares, a Morte depende da ausência da Vida para ser, assim como a Fortuna só é, no contexto de decadência renascentista, pela ausência da Razão². A ideia de oposição continua, ilustrada pela "espada fera" da Ausência, em outros níveis. Por exemplo: apresentada como arma contra o amar, a falta revela-nos o inusitado par "a Morte/ amar-te". Este conjunto, formado por verbo+pronome, ao ser cortado, ferido pela seta que separa a ação do objeto, assemelha-se foneticamente àquele, formado por artigo+substantivo. Assim, da ausência acarretada pela separação (ou pela "descontinuação", como ensina-nos Georges Bataille), a Morte, enfim, encarna-se linguisticamente em "sua imperial potência" de "apartar dum corpo a alma", neste caso, amador e ser amado. A alma, entretanto, já desprovida do corpo perecível, pelo "Amor da Morte, apesar da ausência,/ Do tempo, da Razão e da Fortuna", leva a "triunfante palma”, vitória práma, signo da resistência do Amor.

A ideia do triunfo do Amor sobre Vida e Morte, em especial no âmbito da cultura portuguesa, faz-nos buscar no escritor Mário Cláudio ${ }^{3}$ mais evidências de que o Triunfo do amor português

é como um "centro de resistência ao meio"; corresponde a uma atitude ascética ao recusar as imagens concretas e as suas representações que encarnam o espírito burguês, de acordo com a realidade pessoal tal como ela se demonstra a cada momento (BESSA-LUÍS apud CLÁUDIO, 2005, p. 12).

Com as palavras de Agustina, partimos da referência ao título da obra marioclaudiana lançada em 2004 para tangenciar a resistência que caracteriza o sentimento à portuguesa. Lembremo-nos, por exemplo, de Inês de Castro e Pedro I, ou de Luís de Camões e a Infanta Dona Maria, a propósito, personagens centrais de dois dos contos de Triunfo. A escritora, no prefácio à referida obra, revisa a lúdica atividade de recriar enredos e personagens, a que Mário Cláudio tem se mostrado afeito no conjunto de sua obra. Nesse sentido, as palavras da escritora nos recordam ainda de que essa prática é notadamente empregada na épica camoniana, reflexão coadunada por Jorge de Sena (1980, p. 279) quando afirma que "tudo, para Camões, tem sempre duas faces, como o Jano bifronte, e é da tensão entre elas que salta a chama do Espírito". Assim, resumidamente, o que propomos neste artigo é que a ideia do triunfo do amor como exercício de escrita possibilita que dados da realidade sejam forjados (tanto no sentido de labor quanto no de fingimento) em novas possibilidades de leitura e de discussão sobre o fazer literário. Essa prática pode ser percebida na leitura de obras contemporâneas, como as Mário Cláudio, também estando presente n’Os Lusíadas, cujo pano de fundo é um espetáculo em que as "as armas e os barões assinalados" (CAMÕES, I, 1) cedem vez a um discurso que confere palmas e louros, no final das contas, não aos heróis da pátria, mas à alma 
universal, ao Amor, como podemos ler, por exemplo, na estrofe 89 do Canto IX da épica camoniana. No excerto, que reproduzimos a seguir, a Ilha Namorada surge, já quase ao final da viagem e da narrativa, não apenas como recompensa aos heróis portugueses, mas, especialmente, como uma ode ao Amor:

Que as Ninfas do Oceano, tão fermosas,/ Tétis e a Ilha angélica pintada,/ Outra cousa não é que as deleitosas/ Honras que a vida fazem sublimada./ Aquelas preminências gloriosas,/ Os triunfos, a fronte coroada/ De palma e louro, a glória e maravilha,/ Estes são os deleites desta Ilha.

Ainda pensando sobre a questão lúdica a que nos referimos anteriormente, António José Saraiva, em seus Estudos sobre as artes d'Os Lusíadas, afirma que os exemplos de simetria que se espalham pelo texto camoniano excedem a mera oposição para indicarem um movimento de complementaridade que se dá pela via poética. Portanto, a mesma subjetividade que permite não apenas o diálogo, mas também a fusão em um todo ideal, entre Oriente e Ocidente, a lei de Cristo e a de Maomé, a teologia cristã e a pagã, além de inúmeros outros pares de opostos, possibilita que, conforme pretendemos demonstrar, o par amor e armas - as últimas como sinonímia de um comportamento bélico oposto, inicialmente, ao sentimento amoroso - conduza a uma lei estética capaz de superar determinados estilo e história. A propósito disso, Luiza Nóbrega, em um dos títulos de No reino da água, o rei do vinho: submersão dionisíaca e transfiguração trágico-lírica d'Os Lusíadas (2013), retoma o texto de Saraiva para destacar "Estranhezas e dissimulação" percebidas, em especial, na incomum forma que a épica camoniana tem de narrar os fatos passados em um presente que, para além de trazer ao quadro pintado pelo texto os acontecimentos pretéritos, os sublima em uma grande metáfora facilitadora da simbiose entre opostos. Logo, os tempos mítico e histórico, presentificados na narrativa, fabricam, ainda segundo Saraiva - e, aqui, verificamos a possibilidade de reunião dos vocábulos arma, em sua referência à história bélica portuguesa, amor, que diz respeito ao sentimento sublimado, enfim, na ilha que leva o nome do sentimento, e, finalmente, o ato de armar a cena, o artifício proporcionado pela arte -, um novo tempo. Esse tempo, poético, atualiza paradigmas a partir do gênio do soldado/ poeta que leva sempre "numa mão a espada e noutra a pena”, e que, em última análise, faz de sua figura um espetáculo quase barroco, pois os objetos aparentemente opostos que traz consigo convergem, afinal, para a arte que ele próprio, com sua figura, representa. Desse modo, a épica de Camões metamorfoseia ideais aparentemente distintos, aqui, a saber, arma e amar. O faz não apenas no plano narrativo, visto que "esta a que chamamos a lei estética da objectividade comanda toda a acção do Poema até ao seu desenlace, na Ilha de Vénus" (SARAIVA, 1996, p. 43), mas, de modo especial, na claríssima consciência da poesia camoniana e de seu poder intrínseco de trazer a história ao plano do discutível, do maleável: a arma de Amor é a poesia. 
Relembramos, aqui, as palavras de Vasco Graça Moura (s/d, p. 81), ao reafirmar o caráter duplo da Ilha dos Amores, que é, ao mesmo tempo, utopia e ucronia, por trazer consigo a ideia de infinito ao se deslocar em um não lugar e em um não tempo. Atentemos para a estratégia utilizada por Camões de desenhar seu texto em uma unidade mítico-temporal capaz de reunir, em um só chronos (o presente) e em um topos único (o mar) acontecimentos presentes, pretéritos e futuros, passíveis de acontecerem, unicamente, na ficção. Ainda de acordo com o mesmo crítico, "as forças universais personificadas por Marte e Vénus” (MOURA, s/d, p. 92) aglutinam-se harmonicamente, de modo que

o princípio da guerra (a que obviamente se reconduzem as noções de valor, de furia, de virtú etc.) e o princípio do amor são portanto indissociáveis um do outro, podendo mesmo supor-se neles uma identidade parcial de natureza, ou, como escreve Edgar Wind, the principle of the whole in the part's entails this rather baffling conclusion: that Venus is not only joined to Mars, but that his nature is an essencial part of her own, and vice versa (MOURA, s/d, p. 92).

Dito isso, vale ressaltar o jogo a que nos propomos adentrar, entre os vocábulos armas, amar e armar. Nele, o primeiro elemento estaria para a história de conquistas belicosas portuguesas ${ }^{4}$ assim como o segundo estaria para o desfecho, pretendido pelo poeta, dessa história que, narrada em um estranho tempo presente, convoca ao texto o terceiro vocábulo. Assim, a união entre passado e presente, entre mítico e histórico e, por fim, entre real e ideal, apenas pode ser pensada em um plano artificioso, cuidadosamente idealizado - armado - pelo bardo maneirista.

Ao debruçar-se sobre os atos heróicos do povo lusitano, representado pela nobreza cavalheiresca de Vasco da Gama, o texto épico camoniano, entretanto, aponta características do comandante que escapam, por vezes, à descrição de uma suposta grandeza épica, revelando um homem - e, logo, o povo português, a que também pertenceu Luís de Camões - ao mesmo tempo forte e vulnerável, desbravador e bicho da terra tão pequeno. Assim, a estrutura tradicional épica que confere aos deuses a possibilidade de interferência sobre os problemas humanos, em Camões, apresenta cenas que, dinamicamente, vão do céu à superfície do mar e ao mundo submarino, sempre remetendo à terra, ao amor e à manutenção de certa tradição portuguesa. $\mathrm{O}$ amor, sentimento tão humano, parece ser o motivo da imposição das armas, do amor que é ferido ou que fere e das cenas que são armadas para a encenação vitoriosa desse mesmo amor. Mais que isso, conforme já apontamos, o Amor, grafado com inicial maiúscula, parece ser não apenas o desfecho do grande poema, mas o resultado de uma alquimia entre opostos, a saber, armas e amar, Marte e Vênus, conquistas mercantis e ideal do amor; o futuro da pátria lusíada, conduzida pelo falho Gama, reside, por fim, na Ilha do Amor.

O historiador da arte Arnold Hauser ajuda-nos a pensar na es- 
tratégia humanista do triunfo do amor e no trabalho linguístico cuidadosamente elaborado de que Camões lança mão na construção d'Os Lusíadas. O faz ao observar que "o maneirismo é o primeiro estilo moderno, o primeiro preocupado com um problema cultural e que encara as relações entre tradição e inovação como um problema a ser solucionado por meios racionais" (HAUSER, 2003, p. 371). Portanto, as tendências exegéticas da contemporaneidade, voltando suas preocupações às características formais, ou seja, à expressão artística que se dá no labor estético da palavra, aproximam-se daquela cultura inquieta, gerada por uma situação de crise, que se deu entre o Renascimento e o Barroco. Ainda segundo Hauser,

somos os primeiros a compreender o fato de que os esforços estilísticos de todos os principais artistas do maneirismo [...] estavam concentrados, sobretudo, na dissolução da por demais óbvia regularidade e harmonia da arte clássica e na substituição de sua normatividade superpessoal por características mais sugestivas (HAUSER, 2003, p. 370).

Atentemos, pois, para tais características presentes em alguns trechos d'Os Lusíadas. A sétima estrofe do primeiro canto da epopeia traz, em seus versos, os vocábulos "ramo", "amada" e "armas", em alusão à genealogia do rei português: herdeiro (ramo) de uma linhagem digna do sacrifício de Cristo e, portanto, armada e protegida pelo amor celeste. Entretanto, duas estrofes à frente, o poeta usa o imperativo para sugerir ao rei, figura escolhida, representante da pátria, que se curve, que lance seu olhar ao chão, a fim de ver "um novo exemplo/ De amor dos pátrios feitos valerosos,/ Em versos devulgado numerosos". Valerosos são os feitos dos pátrios que, destaca Camões, não apenas lutam, mas, principalmente, amam, e numerosos são os versos divulgados a seu respeito. $\mathrm{O}$ verso e o povo, os versos do e sobre o povo, a epopeia, portanto, encontra-se na direção aonde aponta o poeta, para que majestade e leitores, anteriores ou contemporâneos, voltem seus olhos a um valor mais alto que se alevanta.

Pensamos, pois, primeiramente, em uma proposta de leitura que prioriza, n'Os Lusíadas, o valor da letra, do belo, do perene, em detrimento do preço mercantil das navegações, leitura que se confirma, por exemplo, com a negativa que se alevantou na praia, contra o projeto marítimo, na voz do Velho do Restelo. Isso nos leva a refletir sobre a modernidade que Camões, se não inaugura, destaca em seus versos, visto que vai ao encontro do que afirma Huizinga:

Seja no mito ou na lírica, no drama ou na epopeia, nas lendas de um passado remoto ou num romance moderno, a finalidade do escritor, consciente ou inconsciente, é criar uma "tensão" que encante o leitor e o mantenha enfeitiçado. Subjacente a toda escritura criadora está sempre alguma situação humana ou emocional suficientemente intensa para transmitir aos outros essa tensão. Mas o problema é que não existe um grande número dessas situações. Em termos gerais, pode-se dizer que essas situações surgem do conflito ou do amor, ou da junção de ambos (HUIZINGA, 1971, p. 148). 
Desse modo, o encantamento com que nos envolve o texto camoniano, dada a tensão a que somos expostos durante a leitura de seus versos, que reúnem enunciantes e enunciados tão distintos, remete-nos ao já mencionado exercício literário de recolher da realidade situações intensas e cobri-las, como destaca Eça de Queirós na epígrafe de A Relíqua, com o "manto diáfano da fantasia". Dessa maneira, a fantasia (literatura, poesia), assim como Amor, no poema que nos serviu de epígrafe, sobrevive à Vida e à Morte, não permitindo que duas almas - duas ideias - sejam descontinuadas do corpo que é o texto. Isso permite que levemos adiante a questão aqui proposta, a de que arma e amar, ideias inicialmente opostas, no contexto da epopeia camoniana, podem ser lidas sob o signo do palco, do espaço da expressão, onde, somente aí, podem amalgamar-se, independente da posição assumida pela letra que diferencia os significados.

Uma derradeira observação a respeito da valoração é-nos apontada por Saraiva que, ao destacar a oposição entre claro e escuro, recorrente n'Os Lusíadas, verifica que a mesma coincide com a oposição entre alto e baixo: "Claro ou alto significa socialmente a nobreza, que tem obrigação de brilhar pelas suas virtudes; escuro ou baixo significa a falta das qualidades próprias de um nobre" (SARAIVA, 1996, p. 54). O crítico segue, em sua análise, verificando que a nobreza dos antepassados portugueses mantém a Pátria sob um signo solar: "a luz mantém-se com os 'costumes altos', embora não se renove” (SARAIVA, 1996, p. 55). Acerca dessas digressões sobre a altura/ baixeza dos valores, Saraiva ainda afirma que

os adjectivos alto e claro revelam o mesmo tropismo solar, pois que o movimento geral da vida para o alto é o movimento para o Sol, e por isso esta associação se encontra em vários poetas. Em Camões, claro reforça a tendência verticalizante expressa em alto, própria de uma postura de combate, e por isso associada a armas (SARAIVA, 1996, p. 55).

Apesar de a claridade estar relacionada, segundo esse raciocínio, à altura e, nesse sentido de verticalização e de combate, às armas, é o próprio Saraiva quem conclui que "também altura e claridade estão relacionadas à ideia de saber" (SARAIVA, 1996, p. 55), finalmente encontrado, por Gama, em seu passeio com Thetis, quando tem a oportunidade de avistar “o globo penetrado por 'lume claríssimo' (...), o prémio supremo dos heróis da navegação” (SARAIVA, 1996, p. 55). Logo, à sequência claro - alto combate - armas juntam-se, paulatinamente, os elementos escuro, baixo e amor que, enfim, culminam na sabedoria ofertada pela máquina amorosa apresentada por Thetis. Portanto, uma vez mais verificamos que a estrutura d'Os Lusíadas excede a tarefa de louvar os feitos pátrios, para, ao reunir opostos, fundi-los na mais refinada representação do ideal finissecular, em que o decadentismo renascentista já cedia espaço a um pensamento barroco, ocupado pela estética maneirista, expressão artística tão familiar à contemporaneidade. 
Retomamos ao Canto I da epopeia, em sua trigésima terceira estrofe, para lermos que Vênus, a deusa do amor e da beleza, de acordo com a mitologia romana, é "afeiçoada à gente Lusitana,/ Por quantas qualidades via nela/ Da antiga, tão amada sua, Romana" língua. Ou seja, a viagem de Vasco da Gama, inicialmente abençoada por Vênus, que ama os portugueses, celebraria o amor para além da "belígera gente" (estrofe 34), indo na contramão da história que divulga as grandes navegações como objetivo primordial da ida de Gama às Índias. Vale, aqui, o destaque do óbvio: quem nos leva pela (contra)mão é o poeta.

Recorrentemente lançando mão de relatos seculares, a literatura e a arte, em geral, criam novas perspectivas, que têm a intenção de oferecer novas interpretações, novos olhares e novas discussões acerca do que seria o mundo e, enfim, o fazer artístico. A anterior aproximação que fizemos entre as práticas de Camões e do também português Mário Cláudio reafirma-se nessa característica contemporânea e, observamos, maneirista, de conceder novos ares e novas leituras a imagens corriqueiras que, pela via da arte, "novos mundos ao mundo irão mostrando" (CAMÕES, II, 45).

A diplomacia de Vasco da Gama, no encontro com o rei de Melinde, sobrepõe-se à luta: as armas que, naturalmente, deveriam ser impostas em combate, são substituídas por uma profusão de cores, tecidos, presentes, gentilezas e histórias, momento em que o comandante da armada portuguesa dá ao Mouro "ilustre relação" de si, da Lei e das armas, ou seja, do povo e da conquista que sua figura representa. Pensamos que, analisando as estrofes que se seguem e que se estendem por outros cantos, a postura cortês, gentil e não poucas vezes carinhosa assumida por Gama - seja no relato do caso de Inês de Castro, no Canto III, com o uso notório de diminutivos que, definitivamente, não caberiam no vocabulário de um belicoso comandante, seja quando, após o combate com os mouros, motivados por Baco a atrapalharem o projeto português, o Amor, sob a figura de Vênus, mais uma vez dá provas de sua afeição pelos viajantes -, o que temos é um desvio ideológico e linguístico. Nessa dobra, apesar das metonímicas armas de um projeto bélico de expansão do comércio ultramarino, o amor, a diplomacia e a humanista valorização da essência do homem impõem-se, coroando o poema inicialmente épico com uma ode ao amor.

Do mesmo modo, no Canto II, o peito ilustre lusitano, cantado anteriormente como imagem forte e bélica, é substituído pelo peito nu de Vênus que, uma vez mais, intercede pelos portugueses pelas vias do amor e da sedução, agora recorrendo a seu pai, Júpiter. Vale recordar que, significativamente, Vênus (amor) é amante de Marte ( $a r m a)$, e que, a fim de conseguir o seu intento junto ao pai, quando surge, nua, à sua frente, a interceder pelo povo lusitano, ela arma um espetáculo fingido, encenando um jogo de sedução em que se apresenta "mais mimosa que triste" (CAMÕES, II, 38). Logo, tendemos a pensar que, se na mitologia, o amor de Vênus atenua Marte e, se no plano narrativo, Vênus ama os belicosos portugueses, por eles lançando mão de artifícios para convencer seu pai a favorecê-los, 
a relação que buscamos destacar entre armas e amor mais uma vez se revela como chave de leitura da epopeia camoniana, em que este se sobrepõe àquelas por meio do fingimento, do espetáculo da palavra que se arma a partir do engenho e da arte do poeta.

No Canto III, em que Vasco da Gama narra o episódio de Inês de Castro, o comandante, no questionamento feito na estrofe $123^{5}$, deixa transparecer sua ética de guerreiro, na qual a espada é arma forjada para a guerra, mas também impotente fio para o transpasso numa dama enamorada. O fato de que Inês tenha sido rainha depois de morta garante, de certo modo, a palma da vitória ao amor e, uma vez mais, assim como apontado no comentário sobre o poema que nos serviu de epígrafe, a relação entre palma e alma mostra-se estreita. Dessa forma, sob a visão neoplatônica camonista, ao amor cabe a palma, apesar da arma e das antíteses que cortam e que segregam a vida.

No Canto V, deparamo-nos com o relato, feito por Gama ao rei de Melinde, do primeiro trecho da viagem. Ao dotar o Adamastor com o falo da voz, o poema, sob o testemunho de Gama, dá início à narrativa do gigante que, ao contar 'a sua 'coyta d'amor', na tradição do amor-paixão na língua galaico-portuguesa, (...) dá-lhe [ao Gama] passagem, vira emblematicamente a porta aberta para o Outro, o Novo Mundo" (SILVEIRA, 2007, p. 51). Uma vez mais, temos o texto camoniano aproximando opostos: a privação metamorfoseia-se em liberdade, pela transformação sofrida pelo amador tornado pedra, a quem foi interditado o acesso ao ser amado. Entretanto, mediando o polo negativo - entendido, em outros momentos, como as armas, o belicoso, mas aqui tomado como a privação - e o seu oposto positivo - o desejo de cumprimento do amor e da liberdade de acesso a uma via impossível -, está a capacidade narrativa, em uma mise en abyme que conduz da passagem pelo Cabo das Tormentas à sua transfiguração em narrativa mitológica. A travessia, narrada por Gama ao rei de Melinde, confere os efeitos pretendidos pelo poeta ao incluir, da maneira como o fez, essa passagem histórica em sua grande obra.

O episódio do Adamastor começa, efetivamente, na estrofe 37 do Canto V, após alguns sinais textuais que o antecipam, tais como nuvens metafóricas que previam a grande tempestade das Tormentas, bem como o metonímico embate entre Veloso e os africanos. O terceiro verso dessa estrofe - "Os mares nunca de outrem navegados" -, entretanto, retoma o terceiro verso da estrofe de abertura d'Os Lusíadas, indicando o retorno, jamais gratuito, que reconvoca o não conhecimento dos mares para transformá-lo, brevemente, em experiência: o reconhecidamente camoniano saber de experiências feito. Entretanto, gostaríamos de chamar atenção para o fato de que o Adamastor, gigante "horrendo e grosso,/ Que pareceu sair do mar profundo" (CAMÕES, V, 40) e que, retomando o tom profético do Velho do Restelo, prevê mortes em seu território, passa, na estrofe 46, a falar de amor. Ressaltamos, ainda, que esse mesmo sentimento, que pode ser lido no Canto III, em que se narra a morte de Inês de Castro, encontra, 
igualmente na figura do Adamastor, a dimensão do castigo. Aqui, uma vez mais, amor e castigo ${ }^{6}$ reúnem-se, na narrativa criada pelo poeta para dobrar, em seu texto, o Cabo das Tormentas, em um espetáculo que joga luz sobre tríade arma, amar, armar e suas possíveis variantes.

O amálgama entre Vênus e Marte, já apontado a partir de citação de Vasco Graça Moura, tem especial relevo no episódio dos Doze de Inglaterra, que é lido no Canto VI d'Os Lusíadas. Nele, ainda segundo o crítico, "amor e valor encontram-se no mesmo rito, no que é também uma fusão de concepções da antiguidade e da cavalaria medieval" (MOURA, s/d, p. 98). Veloso, responsável pela narração do episódio, convém recordar, pode ser lido como um duplo oposto de seu companheiro de navegação, o apaixonado Leonardo. No Canto V, Veloso já é apresentado como um militar de coragem que, ao desembarcar da nau portuguesa para contato com os locais, retorna, amedrontado, à embarcação, fugindo deles. Temos, em primeira instância, o rebaixamento, no sentido rude da palavra, do militar que, acuado, foge, talvez em antecipação ao episódio de amor a ser narrado pela voz da mesma personagem, no canto seguinte. Entretanto, após a narrativa do concílio marítimo, o foco narrativo volta-se à superfície do oceano e, em meio à viagem, Leonardo pede a Veloso que conte à exausta tripulação uma história de amor; este, no entanto, recusa-se a isso - postura, aliás, esperada da figura de um militar. Apesar da inicial negativa, Veloso parece dobrar-se sobre o mesmo esquema proposto, pelo poema, a Vasco da Gama, a saber, o de metamorfosear armas em amor: propondo-se a falar dos feitos ilustres de um grupo de portugueses, conhecido pelo episódio dos Doze de Inglaterra, a aparentemente discreta narrativa de Veloso passa de um tom conflituoso a uma atmosfera de enamoramento, assim como já ocorrido no Canto III, em que Vasco Gama, propondo-se a falar sobre reis, batalhas e conquistas portuguesas, modifica o tom da narrativa para cantar o amor entre Pedro e Inês. Vale insistir no fato de que, no contexto de $O s$ Lusíadas é, também, nos versos articulados para as vozes dessas personagens, que as armas transmutam-se em amor ${ }^{7}$.

Com a descida de Baco ao reino marítimo, cabe a Veloso, em narração intervalar entre o concílio e a posterior ação dos ventos, com a reação das ninfas a favor dos portugueses, amalgamar, uma vez mais, batalha e sentimento amoroso. Mitologicamente, esses duplos são representados, em diálogo com os fatos narrados no Canto VI, pelas intervenções de Marte e Vênus e, no plano da narrativa de Veloso, apresentam-se sob as figuras do Magriço e de sua dama inglesa. Logo, a relevância desse episódio encontraria lugar na essencial fusão que aqui destacamos, entre as armas e o amar, uma vez que, de acordo com análise de Vasco Graça Moura, tal “interpretação teria a vantagem de explicar a necessidade de inclusão do episódio (...), que passaria assim a ser um dos mais importantes do poema no seu significado mítico-filosófico" (MOURA, s/d, p. 99).

Encontramos em Eduardo Lourenço uma explicação que, parece-nos, coaduna as ideias que buscamos, aqui, expor. Explica o estudioso que 
Camões, com sua poesia, em todas as suas contradições, especificamente ao alinhar amor e guerra,

[...] não entreviu - como ninguém com a sua formação o entrevia nessa época - contradição alguma entre as exigências da Fé (o amor cristão, como bem representa o comandante Vasco da Gama) e a exaltação do Império (o que exige as armas, a guerra, elemento também representado por Gama), pela simples razão de que para ele, muito militantemente, a essência desse Império se confundia com a expansão dessa Fé. [...] Tudo isto não afecta a funda humanidade e universalidade da visão camoniana da vida, da história, e do mundo a que nossa imagem de portugueses se sente vinculada. [...] Teremos de o ler e de o ser no que tem de mais humano e vivo como canto do império universal do Amor sob a vestimenta de canto do nosso ex-universal império. É nessa visão universal do Amor que o Renascimento lhe ensinara a ser a essência mesma do Homem consciente do seu valor e dignidade, que Os Lusíadas se transcende como mero espelho particular do que fomos e somos. Esse amor ninguém o transfigurou no seu espírito e na sua imaginação como aquele que de si mesmo disse que "só de amor viveu e escreveu". Embebida nesse Amor, a sua vida peregrina e errante, amarga e desventurada se fez verbo e o verbo se fez Pátria Canto. É a nossa. Por isso aqui estamos (LOURENÇO, 1983, p. 106-107. Adendos nossos).

A longa citação de "Camões ou a nossa alma", texto que revela uma identidade portuguesa fundada em sua literatura, vai ao encontro da ideia de que os versos camonianos, em sua lírica ou em sua épica, calcados na universalidade do amor, são passíveis de uma leitura atemporal, apesar de relatarem os sentidos e percepções de determinada época, a do poeta. Entretanto, concordamos com Arnold Hauser quando afirma que o nosso tempo é o responsável por identificar a presença de uma estética maneirista entre o Renascimento e o Barroco, dada a semelhança crítica que somos capazes de observar entre os nossos dias e aqueles.

Muitas são as ocorrências das palavras arma e amar, bem como suas derivadas, no âmbito d'Os Lusíadas; optamos por aqui destacar algumas dessas ocorrências, em que fica clara a hipótese que buscamos, neste artigo, demonstrar. Sendo literatura, o texto de Camões cumpre seu papel (amoroso, talvez?) de ser palco para um espetáculo cujas palavras, magnificamente organizadas, desarmam qualquer possibilidade de leitura acomodada, especialmente a leitura contemporânea que se faz de seu texto. Desse modo, metalinguisticamente, unimo-nos a Eduardo Lourenço para ratificarmos o motivo de aqui nos encontrarmos: o poeta se fez verbo e o verbo se fez pátria. Mesmo ferida pela espada da ausência e do tempo, a Fortuna da alma camoniana, séculos depois, é ainda portadora da palma que a mantém viva. Armemo-nos de amor, amemos; armemos, pois, espetáculos para o seu Canto. 


\section{REFERÊNCIAS BIBLIOGRÁFICAS}

BATAILLE, Georges. O erotismo. Tradução de Fernando Scheibe. Belo Horizonte: Autêntica, 2013.

CAMÕES, Luís Vaz de. Sonetos. 20--. Disponível em: < http://www. dominiopublico.gov.br/download/texto/bv000164.pdf>. Acesso em: 10 jul. 2019.

Porto: Porto Editora, 1987.

CLÁUDIO, Mário. Itinerários. Lisboa: Dom Quixote, 1993.

Peregrinação de Barnabé das Índias. Lisboa: Dom Quixote, 1998.

Triunfo do amor português. Lisboa: Dom Quixote, 2005.

. Os naufrágios de Camões. Lisboa: Dom Quixote, 2017.

HAUSER, Arnold. História social da arte e de literatura. Tradução de Álvaro Cabral. São Paulo: Martins Fontes, 2003.

HUIZINGA, Johan. Homo ludens: o jogo como elemento da cultura. São Paulo: Perspectiva/ Editora da USP, 1971.

LOURENÇO, Eduardo. Camões ou a nossa alma. In: . Camões e a identidade nacional. Lisboa: INCM, 1983. p. 99-107. s/d.

MOURA, Vasco Graça. Luís de Camões: alguns desafios. Lisboa: Vega,

NÓBREGA, Luiza. No reino da água o rei do vinho: triunfo de Baco n’Os Lusíadas. Natal: Editora da UFRN, 2013.

SARAIVA, António José. Estudos sobre a arte d’Os Lusíadas. Lisboa: Gradiva, 1996.

SENA, Jorge de. Aspectos do pensamento de Camões através da estrutura linguística de Os Lusíadas. In: Trinta anos de Camões: 1948-1978 (Estudos camonianos e correlatos). Vol. 1. Lisboa: Edições 70, 1980. p. 274-286.

SILVEIRA, Jorge Fernandes da. O Tejo é um rio controverso: António José Saraiva contra Luís Vaz de Camões. Rio de Janeiro: 7Letras, 2007.

Recebido para publicação em 01/03/19

Aprovado em 29/06/19

\section{NOTAS}

1 Mariana Caser da Costa é doutora em Literatura Comparada pela Universidade Federal Fluminense. Possui o título de mestre em Estudos Literários, na subárea Literatura Portuguesa, sendo, ainda, especialista em Literaturas e Culturas de Língua Portuguesa: Portugal e África pela mesma Instituição. Atualmente, é revisora do quadro permanente da Fundação Centro de Ciências e Educação Superior a distância do Estado do Rio de 
Janeiro - Fundação Cecierj, já tendo atuado como professora da Faculdade de Educação e Tecnologia do Estado do Rio de Janeiro (Faeterj)/ Petrópolis e em instituições de ensino das redes particular e pública.

2 Recordemo-nos da antinomia marcadamente presente na obra camoniana, de maneira pontual apontada nos primeiros versos do soneto: "Verdade, Amor, Razão, Merecimento/ qualquer alma farão segura e forte;/ porém, Fortuna, Caso, Tempo e Sorte,/ Têm do confuso mundo o regimento" (CAMÕES, 20--).

3 Mário Cláudio é o pseudônimo de Rui Manuel Pinto Barbot Costa, escritor português contemporâneo de estética reconhecidamente barroca, autor de obras que se caracterizam por um tom autoirônico, autorreferencial e metalinguístico, e que destacam a qualidade lúdica da literatura, bem como de outras formas de expressão artística. A fim de demonstrar a presença camoniana no universo da obra deste escritor, convém ressaltar, pelo menos, quatro textos de sua autoria: "2380 ano de Camões 2380" e "De Barnabé, mestre-cozinheiro da Nau-Capitânia, na primeira viagem a caminho das Índias", contos de Itinerários (1993), além dos romances Peregrinação de Barnabé das Índias (1998) e, mais recentemente, Os naufrágios de Camões (2017), em que Mário Cláudio subverte a intangibilidade do épico e o traz para a contemporaneidade, num profícuo gesto de contrabando cultural.

4 Pensamos, com isto, na questão do valor, mais alto ou mais baixo, que se alevanta da épica camoniana. Contudo, não é esse o cerne deste artigo e tememos adentrar um campo que fugiria ao tópico a que nos propomos desenvolver. Contudo, convém, aqui, brevemente recordar versos d'Os Lusíadas, que nos oferecem pistas para uma discussão - inclusive já abordada em curso proferido pelo professor Luis Maffei, na UFF - acerca do valor n’Os Lusíadas: "Cessem do sábio Grego e do Troiano/ As navegações grandes que fizeram;/ Cale-se de Alexandro e de Trajano/ A fama das vitórias que tiveram;/ Que eu canto o peito ilustre Lusitano,/ A quem Neptuno e Marte obedeceram./ Cesse tudo o que a Musa antiga canta,/ Que outro valor mais alto se alevanta" (CAMÕES, I, 3). Antes do imperativo, o poeta fala das "armas" e dos "barões assinalados" portugueses, bem como das "memórias gloriosas/ Daqueles Reis que foram dilatando/ A Fé, o Império, e as terras viciosas” (Ibidem, I, 2-3), a serem cantados por ele que, contudo, carrega consigo "um novo engenho ardente", ou seja, um desejo renovado, de um canto novo, cujo valor se elevaria não a partir dos feitos grandiosos, mas na suposta baixeza do livro, do poema que ele tem em mãos e para o qual, estrofes à frente, solicita ao rei que baixe seus olhos.

5 "Que furor consentiu que a espada fina,/ Que pôde sustentar o grande peso/ Do furor Mauro, fosse alevantada/ Contra hua fraca dama delicada?"

6 Não podemos deixar de nos lembrar do texto de Walter Benjamin acerca do drama barroco alemão, em que, dentre outros objetos, fala da oposição, neste texto destacada, entre jogo e luto e suas possíveis figurações: amor e guerra, claridade e escuridão, altura e baixeza etc. (Ver: BENJAMIN, Walter. Origem do drama barroco alemão. Tradução, apresentação e notas: Sergio Paulo Rouanet. São Paulo: Brasiliense, 1984.

7 Recordamo-nos, neste momento, da sétima estrofe do Canto I, anteriormente referida neste texto, em que surge a palavra "valerosos", a que relacionamos, por semelhança, a Veloso. Essa atribuição que ousamos propor, da alcunha de "Veloso, o valoroso", respalda-se no duplo valor que essa personagem representa e, se quisermos retomar a questão da altura e da baixeza, podemos, também, notar que os "altos" valores ético-militares que Veloso representa são substituídos, na narrativa, pela "baixeza" tão humana do sentimento amoroso. 